\title{
Gastrointestinal symptoms associated with gastroesophageal reflux disease, and their relapses after treatment with proton pump inhibitors: A systematic review
}

\author{
Mousalreza Hosseini ${ }^{1}$, Roshanak Salari ${ }^{2}$, Somayeh Shariatmaghani ${ }^{3}$, Batul Birjandi ${ }^{4}$, Masoumeh Salari ${ }^{3}$
}

${ }^{1}$ M.D., Gastroenterologist, Assistant Professor, Ghaem Hospital, Faculty of Medicine, Mashhad University of Medical Sciences, Mashhad, Iran

${ }^{2}$ Ph.D. of Drug Control, Assistant Professor, Department of Traditional Persian Pharmacy, School of Persian and Complementary Medicine, Mashhad University of Medical Sciences, Mashhad, Iran

${ }^{3}$ M.D., Internist, Assistant Professor, Ghaem Hospital, Faculty of Medicine, Mashhad University of Medical Sciences, Mashhad, Iran

${ }^{4}$ M.D., Internist, School of Medicine, Mashhad University of Medical Sciences, Mashhad, Iran

Type of article: Systematic review

\begin{abstract}
Gastroesophageal reflux disease (GERD) is a common functional gastrointestinal disorder with significant effects on the quality of life. The burden of GERD is soaring in Asia. Preventing symptom relapse is a therapeutic goal in GERD patients. Since proton pump inhibitors (PPI) are the first-line treatment of GERD, drug failure has become a major problem in the treatment procedure. We reviewed the literature in order to find articles related to comorbidities and symptoms affecting GERD from 1980 to 2015 via PubMed and Google Scholar using keywords such as 'Gastroesophageal reflux disease', 'Gastrointestinal symptoms' and Boolean operators (such as AND, OR, NOT). Due to the cost of PPI therapy and the high rate of GERD relapse after PPI therapy, demand for continuing this type of treatment is decreasing. Thus, we need to discover new approaches to treat the disease and also investigate the relationship between the treatment of GERD and its comorbidities and symptoms such as functional constipation.

Keywords: Gastroesophageal reflux disease (GERD), Proton pump inhibitors (PPI), Comorbidities, Relapse
\end{abstract}

\section{Introduction}

The chronic or recurrent gastrointestinal symptoms which cannot be explained through structural or biochemical abnormalities are referred to as functional gastrointestinal disorders (FGIDs). Such disorders are highly prevalent (1). GERD is a common FGID with a significant impact on the quality of life (2). Approximately $50 \%$ of infants younger than 3 months are affected by GERD (3). In this disorder, stomach acid or sporadic stomach content moves up from the stomach into the esophagus. It has been reported that permanent or temporary changes in the barrier between the stomach and the esophagus like abnormal movements of the lower esophageal sphincter and hiatal hernia are the major factors likely to lead to GERD. The burden of GERD is soaring in Asia and the majority of GERD patients are known to have non erosive reflux disease (NERD) (4). Proton pump inhibitors (PPI) and H2 receptor blockers or antacids are recognized as the first-line treatment of GERD. Preventing symptom relapse is a therapeutic goal in GERD patients (5). Therefore, PPI failure has turned into a major problem in the treatment procedure of GERD. Since there is a fair chance of GERD to be overlapped with other diseases, it is likely that the disease originates from the NERD phenotype leading to drug failure in GERD patients (6). As a result, we need to discover new approaches as to treat or prevent GERD. Several studies have focused on the treatment of GERD comorbidities and its associated symptoms such as FC in the face of treatment $(7,8)$. GERD and FC are the most common causes of referral to pediatricians within the first six months of life (2). Since a number of studies have indicated a significant relationship between GERD and FC, investigating the influence of these mechanisms on each

\section{Corresponding author:}

Assistant Professor Dr. Masoumeh Salari, Ghaem Hospital, Faculty of Medicine, Mashhad University of Medical Sciences, Mashhad, Iran. Tel: +98.9155050927, Email: Salarim@mums.ac.ir

Received: September 10, 2016, Accepted: January 25, 2017, Published: June 2017

iThenticate screening: January 24, 2017, English editing: February 10, 2017, Quality control: April 14, 2017

(C) 2017 The Authors. This is an open access article under the terms of the Creative Commons Attribution-NonCommercialNoDerivs License, which permits use and distribution in any medium, provided the original work is properly cited, the use is non-commercial and no modifications or adaptations are made. 
other may lead us to a better understanding of the appropriate treatment for GERD. As such, the current systematic review aimed to answer the following questions:

1) What are the most common comorbidities in GERD patients?

2) What are the most frequent symptoms associated with GERD?

3) Is there a relationship between the changes in bowel function and reflux?

4) Is there a distinct relationship between GERD and FC?

5) Could PPI therapy act as the appropriate treatment for GERD?

6) What is the rate of symptom relapse in GERD after PPI treatment?

\section{Material and Methods}

\subsection{Literature search strategy}

We reviewed the literature in order to find articles related to comorbidities and symptoms affecting GERD from 1980 to 2015 via PubMed and Google Scholar, using keywords such as 'Gastroesophageal reflux disease', 'Gastrointestinal symptoms' and Boolean operators (such as AND, OR, NOT), which are listed as follows: 1) Gastroesophageal reflux disease (GERD), 2) Gastric reflux disease, 3) Acid reflux disease 4) Functional gastrointestinal disorders (FGID), 5) Esophageal disease, 6) Functional constipation (FC), 7) Constipation, 8) Gastrointestinal symptoms, 9) Risk factors of gastroesophageal reflux disease, 10) Risk factors of gastrointestinal disease, 11) Gastrointestinal symptoms, 12) Esophageal disease, 13) Functional bowel disorders (FBD), GERD, 15) Gastrointestinal motility disorders, 16) Proton pump inhibitors (PPI), 17) Esophageal disease symptoms, 18) Gastroesophageal reflux disease symptoms, 19) GERD recurrence, 20) GERD relapse, and 21) H2 blocker.

\subsection{Exclusion criteria}

Expert opinions, consensus statements, case reports, editorials and letters, and qualitative studies were excluded from this review. The selected studies were published in English, but studies conducted in other languages were excluded.

\subsection{Search strategy}

Since a variety of different factors were assessed in the selected studies, the comparison between them could not be done in a straight forward manner and all the articles were evaluated in terms of the inclusion criteria in the present study. In total, 751 items found and 50 articles, which mainly focused on the comorbidities and the symptoms affecting GERD, PPI therapy and the rate of symptom relapse, were included in the current review. Ultimately, the findings of the selected articles were summarized in different subsections.

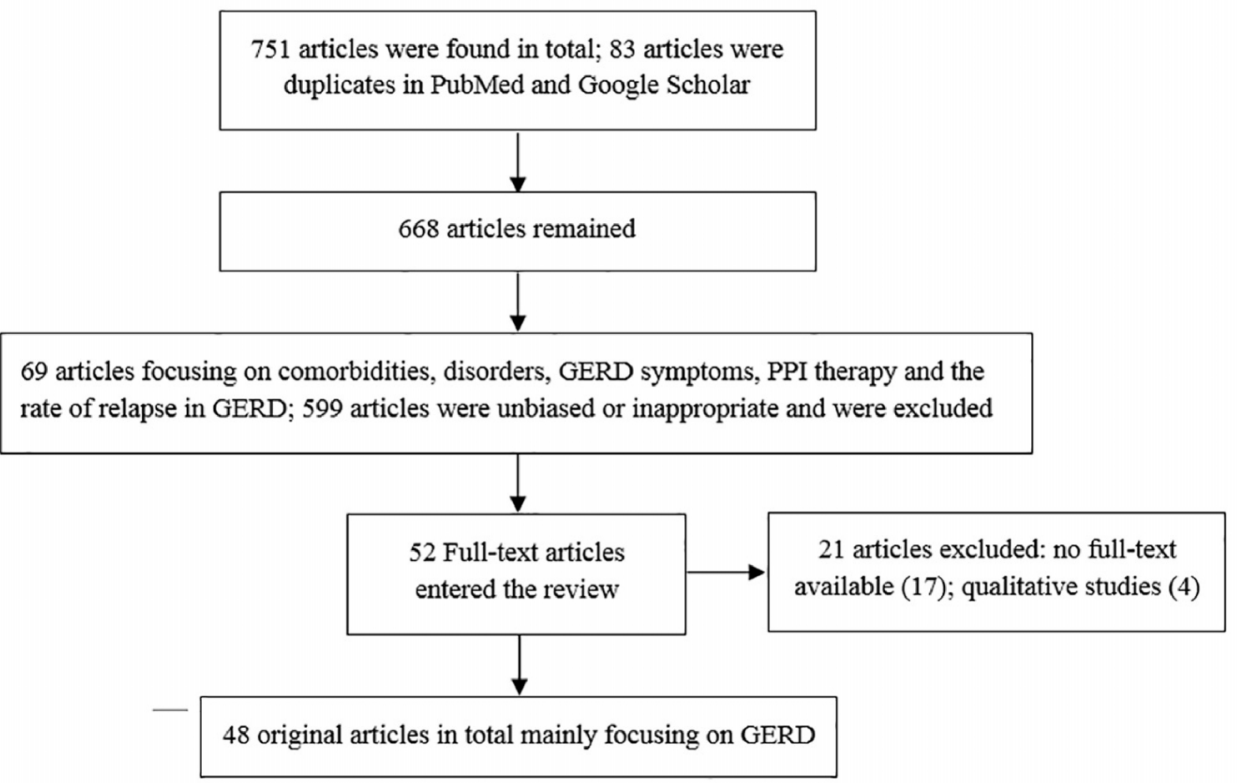

Figure 1. PRISMA Flow Diagram: The screening process of articles in the current study 
All the repetitive and irrelevant studies were removed from this systematic review. Moreover, the remaining articles were investigated as to discover the comorbidities and symptoms affecting GERD, the treatment procedure and the rate of symptom relapse in the GERD patients who were treated by PPI. These articles were evaluated in their full text after the screening step was complete, and the references were carefully organized during the next steps. The quality assessment of articles was based on two standards, CONSORT for clinical trials and PRISMA for review articles. The screening procedures are illustrated in the PRISMA flow diagram (Figure 1).

\section{Results and discussion}

\subsection{The most common comorbidities in GERD patients}

To the best of our knowledge, GERD is a prevalent type of FGID which exerts a negative effect on the quality of life. The study of Indrio et al. claimed that infantile colic, gastroesophageal reflux and constipation are the most common causes of referral to pediatricians within the first six months of life. It might result in the patient's hospitalization, use of medications as well as anxiety and waste of time on behalf of parents (2). Digestive disorders associated with GERD have been assessed in many studies. According to the study of Rasmussen et al., which aimed to investigate the prevalence and overlap of GERD, functional dyspepsia (FD) and irritable bowel syndrome (IBS) in a Western population, the prevalence of GERD was reported to be $11.2 \%$. Furthermore, the overlap between two or three of these disorders (GERD, FD, and IBS) was as much as $6.5 \%$. Also, $30.7 \%$ of the patients who showed one or more of the factors of GERD, FD and IBS disorders, were found to have an overlap between two or all these disorders. Their study proved an overlap to be probable as well as frequent between these disorders (9). The results of De Vries et al.'s study indicated that FD and IBS were more prevalent in GERD patients compared to the general population (10). For this reason, the recognition of the diseases and the associated symptoms plays a major role in the treatment, elimination and prevention of this disease. Similar to Rasmussen et al and De Vries et al., the study of Pimentel et al. was indicative of a higher prevalence of IBS in the subjects with GERD compared with those without GERD. Another study conducted on a Korean population revealed that the overlaps between GERD, dyspepsia and IBS are frequent in the general population occurring in anxious people. In total, compared with GERD, dyspepsia, and IBS alone, a significant difference was detected between anxiety and GERD, dyspepsia and IBS overlap (11). The overlap between GERD and IBS was mentioned a lot (12-17). GERD is known as a psychosomatic disease which involves complex biopsychosocial problems (18) which have a negative effect on the individuals' quality of life (19). According to the results of the aforementioned studies, IBS, among functional bowel disorders, is proven to be most significantly associated with GERD. Moreover, there seems to be an undeniable correlation between GERD and functional bowel disorders. Consequently, we attempted to reorganize the gastrointestinal and functional bowel disorder symptoms and their association with GERD (20-21). The most frequent comorbidities and the rate of overlap in GERD patients based on different studies are shown in Table 1.

\subsection{The relationship between changes of bowel function, constipation and GERD}

The findings of epidemiological studies in the adult population are suggestive of a significant overlap between the functional disorders of the digestive system. As such, two major and integral components of childhood functional gastrointestinal disorders are FC and GERD (22-25). Reorganization of GERD symptoms as well as the causes of its association with FC are paramount due to their remarkable impact on the patient's quality of life. For this reason, we also attempted to investigate the correlation between GERD and FC. Evidently, there is a relationship between GERD disorder and functional bowel diseases (FBD). Since FC is one of the most prominent symptoms of FBD, there might also be comorbidity between the GERD disorder and FC. This finding has been confirmed by several studies. In this regard, the study of Zeitoun et al. showed that $84 \%$ of the patients with Ehlers-Danlos syndrome (EDS) also suffered from FBD. Overall, a significant correlation was found between FBD and GERD (23-24). Jiang et al. aimed to assess the prevalence of common symptoms of gastrointestinal and GERD combined with functional bowel disorders (FBD). The frequency and severity of GERD symptoms were measured by a Chinese Reflux Disease Questionnaire (RDQ). Approximately $10 \%$ of the patients, who showed symptoms of GERD, were really diagnosed with this disease (8). Another study was performed by Baran et al. to evaluate the frequency of GERD in children with FC. According to the results of that study, delayed gastric emptying symptoms were more prevalent in the patients with FC. In addition, pyrosis, hiccups and belching were observed to be common in FC patients with and without acid reflux (22). 
Table 1. The most common comorbidities in GERD patients

\begin{tabular}{|c|c|c|c|}
\hline $\begin{array}{l}\text { Ref. } \\
\text { no. }\end{array}$ & Country & $\begin{array}{l}\text { Comorbidities, Diseases } \\
\text { and Disorders }\end{array}$ & Results and Rate of Overlap \\
\hline 9 & Denmark & $\begin{array}{l}\text { Functional dyspepsia } \\
\text { (FD) and irritable bowel } \\
\text { syndrome (IBS) }\end{array}$ & $\begin{array}{l}\text { The overlap between GERD, FD, and IBS was } 6.5 \% .30 .7 \% \text { of } \\
\text { the patients with one or more of the GERD, FD and IBS criteria } \\
\text { had overlap between two or all three disorders. }\end{array}$ \\
\hline 16 & UK & $\begin{array}{l}\text { Increased prevalence of } \\
\text { GERD and IBS symptoms } \\
\text { was associated with } \\
\text { coeliac disease and IBD }\end{array}$ & $\begin{array}{l}\text { Odds ratio of coeliac disease and IBD were } 6.8 \% \text { and } 2.2 \% \text { in } \\
\text { GERD patients with severe symptoms. }\end{array}$ \\
\hline 20 & USA & IBS & $\begin{array}{l}71 \% \text { of GERD patients had IBS and there was a higher } \\
\text { prevalence of IBS in subjects with GERD compared with non- } \\
\text { GERD subjects. }\end{array}$ \\
\hline 10 & Netherlands & $\begin{array}{l}\text { FD, IBS and both FD and } \\
\text { IBS }\end{array}$ & $\begin{array}{l}25 \%, 35 \% \text {, and } 5 \% \text { of GERD patients had FD ( } 14 \% \text { in general } \\
\text { population), IBS ( } 0.6-6 \% \text { in general population), and both FD } \\
\text { and IBS, respectively. }\end{array}$ \\
\hline 11 & Korea & $\begin{array}{l}\text { GERD, dyspepsia and } \\
\text { IBS }\end{array}$ & $\begin{array}{l}\text { Overlaps between GERD, dyspepsia and IBS were observed in } \\
2.3 \% \text { and } 2 \% \text {. Overlaps between dyspepsia and IBS were } \\
\text { observed in } 2 \% \text { and } 1.3 \% \text { of the population. }\end{array}$ \\
\hline 12 & Iran & $\begin{array}{l}\text { IBS, GERD and } \\
\text { dyspepsia }\end{array}$ & $\begin{array}{l}74.7 \% \text { and } 77.9 \% \text { of IBS patients simultaneously suffered from } \\
\text { GERD and dyspepsia symptoms. Also } 66 \% \text { of GERD patients } \\
\text { had dyspepsia. }\end{array}$ \\
\hline 17 & Italy & $\begin{array}{l}\text { IBS and Functional } \\
\text { heartburn }(\mathrm{FH})\end{array}$ & $\begin{array}{l}\text { Possible concomitance of GERD or FH with IBS and the } \\
\text { pathophysiological relationships between these disorders. }\end{array}$ \\
\hline 14 & Iran & $\begin{array}{l}\text { IBS and functional } \\
\text { symptoms }\end{array}$ & $\begin{array}{l}63.6 \% \text { of IBS subjects and } 34.7 \% \text { of non-IBS patients suffered } \\
\text { from GERD }(p<0.05) .33 .9 \% \text { of GERD patients compared to } \\
13.5 \% \text { of non-GERD patients had Rome criteria. }\end{array}$ \\
\hline 13 & Singapore & Dyspepsia and IBS & $\begin{array}{l}\text { Dyspepsia and irritable bowel syndrome are co-existing } \\
\text { disorders with GERD. }\end{array}$ \\
\hline 8 & China & $\begin{array}{l}\text { Chronic abdominal } \\
\text { pain/bloating, chronic } \\
\text { diarrhea/constipation, } \\
\text { FBD, IBS and functional } \\
\text { constipation }\end{array}$ & $\begin{array}{l}25.2 \%, 14 \%, 10.3 \% \text {, and } 7.5 \% \text { of GERD patients had chronic } \\
\text { bloating, chronic constipation, IBS and FC and the rate of these } \\
\text { symptoms was higher in GERD patients than non-GERD } \\
\text { patients. In total, the rate of GERD combined with chronic } \\
\text { bloating and constipation had overlaps with IBS and FC. }\end{array}$ \\
\hline
\end{tabular}

\subsection{Treatment of GERD symptoms with proton pump inhibitors (PPI)}

Proton pump inhibitors (PPI) and $\mathrm{H} 2$ receptor blockers or antacids are the first-line treatment of GERD. In patients with certain conditions or the ones who do not show signs of improvement, surgery might be optional to treatment. Normally, it occurs in $10-20 \%$ of the population in Western countries. Due to the fact that there is evidence of overlap in GERD, IBS and FD patients, and also because of the lack of major pharmacological breakthrough in the treatment of this overlap, the study of Monnikes et al. was performed in order to evaluate the stability of GERD healing process and determine whether the effects of PPI treatment on the GERD would also apply to symptoms of IBS and FD. According to their findings, pantoprazole decreased the prevalence of GERD combined with FD, IBS or reflux symptoms. After discontinuing the medication, the rates of FD and IBS were stabilized at a relatively low level. However, reflux symptoms increased again after the cessation of the medication (26). Another study which was performed in Pakistan in order to evaluate the rate of PPI use in GERD patients with typical symptoms, showed that the omeprazole was the medication of choice (16). The study of Yamaji et al. was conducted in order to determine whether the symptoms of GERD would improve by the prokinetic activity of mosapride combined with PPI. According to their results, no additional improvements of reflux symptoms were observed in the patients who used mosapride combined with PPI compared to those who only received PPI (27). In the study of Remes-Troche et al, the severity of GERD symptoms decreased by at least $80 \%$ from the baseline after the treatment with pantoprazole magnesium (28). The study of Moraes-Filho et al. was designed to compare the efficacy of pantoprazole and esomeprazole in GERD patients. According to the results of that study, no significant differences were found in the improvement of GERD patients in four weeks. At week 8, GERD symptom had shown a more noticeable improvement in the patients who used pantoprazole (91.6\%) compared to the patients who had used 
esomeprazole (86.0\%) $(\mathrm{p}=0.0370)(29)$. Another study which was performed to evaluate the safety and efficacy of esomeprazole combined with flupentixol/melitracen for the treatment of GERD patients with emotional disorders, proved the combination therapy to be more effective and safer in the treatment of patients who had gastroesophageal reflux (30). The study of Chiu et al. aimed to investigate the efficacy and safety of sodium alginate suspension compared to omeprazole NERD patients. According to their study, sodium alginate was as effective as omeprazole for symptomatic relief in patients with non-erosive reflux disease (4). Similar to the study of Chiu et al. (4), omeprazole $20 \mathrm{mg}$ was used for the treatment of reflux symptoms in the study of Abbasinazari et al. Omeprazole plus SR (Sustained Release) baclofen was administered versus omeprazole $20 \mathrm{mg} / \mathrm{d}$ plus placebo. The results of the study revealed that SR baclofen plus omeprazole is more effective than omeprazole alone in the treatment of reflux symptoms (heartburn and regurgitation) (31). Another study which was conducted to compare the effects of singledose morning versus nighttime once-daily omeprazole/sodium bicarbonate (Zegerid (囚) (IR-OME) in patients with esophagitis and symptoms of gastroesophageal reflux, showed that the reflux esophagitis and GERD symptoms improved after taking IR-OME (32-33). According to the study of Kim et al., poor response to PPI treatment is a result of psychological factors, sleep dysfunction and BMI lower $23 \mathrm{~kg} / \mathrm{m}$ in patients with GERD symptoms (34). The study of De Milliano et al. aimed to determine the effects of a mixture of probiotics in the treatment of constipation during pregnancy (35). According to the study of Perry et al., in western societies, $10 \%$ of the population is affected by GERD (36). The disease is known to have cost the United States healthcare system over 9 billion dollars per year (37). Drug failure is experienced by $30-40 \%$ of the patients who receive PPI therapy. The recent findings are indicative of the fact that the risk of complications is increasing among these patients. Regarding the diverse number of patients who experience medically inappropriate treatments and the number of surgeries, there is a substantial therapeutic gap in the management of GERD (36). For this reason, we need to discover new approaches to treat or prevent GERD. Several studies have focused on diet therapy $(1,38,39)$ while some others have emphasized on the treatment of GERD comorbidities such as IBS and the associated symptoms like FC $(7,8)$ for the treatment, elimination or prevention of GERD.

\subsection{Relapse of GERD symptoms after PPI and H2 blocker therapy}

As we know, GERD treatment is highly costly. In some studies, step-down from PPI is used in order to obtain a less expensive therapy. In the study of Inadomi et al., a total of 117 subjects received treatment from step-down to single-dose PPI. The majority of the patients did not report recurrent symptoms of reflux symptom during the 6 months and their quality of life did not alter significantly. However, the rate of dyspepsia was observed to increase (40-43).

Table 2. The rate of GERD symptom relapse after PPI or H2 blocker therapy

\begin{tabular}{|c|c|c|c|}
\hline $\begin{array}{l}\text { Ref. } \\
\text { no. }\end{array}$ & Country & Number/ Dosage & Rate symptom relapse \\
\hline 43 & USA & $\begin{array}{l}117 \text { subjects were treated with } \\
\text { step-down to single-dose PPI }\end{array}$ & $\begin{array}{l}79.5 \% \text { of the patients did not report recurrent symptoms of } \\
\text { reflux during the } 6 \text { months }\end{array}$ \\
\hline 5 & Japan & $\begin{array}{l}41 \text { patients treated by } 15 \mathrm{mg} / \mathrm{d} \text { of } \\
\text { lansoprazole or } 15 \mathrm{mg} \text { of } \\
\text { lansoprazole and } 300 \mathrm{mg} / \mathrm{d} \\
\text { rebamipide for } 8 \text { weeks }\end{array}$ & $\begin{array}{l}\text { After } 12 \text { months, } 52.4 \% \text { and } 20 \% \text { of the patients were } \\
\text { treated by lansoprazole and lansoprazole plus rebamipide } \\
\text { experienced recurrence of symptoms }(\mathrm{p}<0.05)\end{array}$ \\
\hline 44 & Japan & $\begin{array}{l}99 \mathrm{patients} \mathrm{treated} \mathrm{by} \mathrm{rabeprazole} \\
(10 \mathrm{mg} / \text { day }), \text { omeprazole } \\
(20 \mathrm{mg} / \text { day }) \text { or lansoprazole } \\
(15 \mathrm{mg} / \text { day })\end{array}$ & $\begin{array}{l}\text { After } 6 \text { months, the recurrence rate was } 25 \%, 30.8 \% \text {, and } \\
4.4 \% \text { in patients who were treated by omeprazole, } \\
\text { lansoprazole, and rabeprazole, respectively. }\end{array}$ \\
\hline 46 & Italy & $\begin{array}{l}105 \text { patients treated by proton- } \\
\text { pump inhibitor (PPI) for } 8 \text { weeks }\end{array}$ & $\begin{array}{l}\text { Recurrence of GERD-rs was observed in about } 20 \% \text { of } \\
\text { patients. This was found out after } 12,18 \text {, and } 24 \text { months }\end{array}$ \\
\hline 47 & Japan & $\begin{array}{l}17 \text { handicapped children; } \\
\text { Famotidine } 1 \text { to } 2 \mathrm{mg} / \mathrm{kg} \text {, twice a } \\
\text { day }>10 \mathrm{~kg} \text { three times a day }<10 \\
\mathrm{~kg} \text {. }\end{array}$ & $\begin{array}{l}\text { Reduction of vomiting or hematemesis (or both) within two } \\
\text { weeks in } 70 \% \text { of cases and within three weeks in } 94 \% \text {. } \\
\text { Famotidine was effective in } 29 \% \text { and moderately effective } \\
\text { in } 41 \% \text {; no side effects were observed }\end{array}$ \\
\hline 45 & UK & $\begin{array}{l}156 \text { patients; Omeprazole } \\
(20 \mathrm{mg} / \mathrm{d}) \text { and cimetidine }(400 \mathrm{mg} \\
\text { qds) prescribed for } 4 \text { weeks }\end{array}$ & $\begin{array}{l}\text { The median time to symptomatic relapse was longer in } \\
\text { patients receiving omeprazole ( } 169 \text { vs. } 15 \text { days })(p=0.0001)\end{array}$ \\
\hline
\end{tabular}


In a study performed by Yoshida et al., it was suggested that rebamipide plus lansoprazole could be effective in preventing the symptom relapse of GERD in the long run, and it could also be used as a maintenance treatment for this disorder (5). According to another study, the recurrence rate was $25 \%, 30.8 \%$, and $4.4 \%$ in the patients receiving treatment with omeprazole, lansoprazole, and rabeprazole, respectively (44). In the other study on the same subject, Omeprazole was more effective than cimetidine in preventing the recurrence of GERD-associated heartburn (45). The study of Usai et al. emphasized the role of a gluten-free diet (GFD) in diminishing GERD symptoms as well as in preventing the recurrence of these symptoms (46). The study of Miyake et al was performed to assess the effects of famotidine to prevent the recurrence of reflux esophagitis. According to their results, improvements were observed within seven days (47). The study of Caro et al. showed that PPIs were found to be effective in the recovery of erosive esophagitis and decreasing relapse rates compared to ranitidine and placebo (48). The rates of GERD symptom relapse after PPI orH2 blocker therapy are shown in Table 2.

\section{Conclusions}

GERD has a negative impact on the individuals' quality of life. Moreover, an undeniable connection seems to exist between GERD and other GI disorders. Therefore, investigating the relationship between the treatment of GERD and its comorbidities and symptoms such as FC is of paramount importance. Due to the cost of PPI therapy and the high rate of GERD relapse after PPI therapy, demand for continuing this type of treatment is decreasing. Thus, we need to discover new approaches as to treat or prevent GERD bridging the therapeutic gap in the management of this disease.

\section{Acknowledgments:}

This work was supported by a grant from Ghaem Hospital and the Vice Chancellor of Research of Mashhad University of Medical Sciences.

\section{Conflict of Interest:}

There is no conflict of interest to be declared.

Authors' contributions:

All authors contributed to this project and article equally. All authors read and approved the final manuscript.

\section{References:}

1) Bergmann MM, Caubet JC, McLin V, Belli DC, Schappi MG, Eigenmann PA. Common colic, gastroesophageal reflux and constipation in infants under 6 months of age do not necessitate an allergy work-up. Pediatr Allergy Immunol. 2014; 25(4): 410-2. doi: 10.1111/pai.12199. PMID: 24438166.

2) Indrio F, Di Mauro A, Riezzo G, Cavallo L, Francavilla R. Infantile colic, regurgitation, and constipation: an early traumatic insult in the development of functional gastrointestinal disorders in children?. Eur J Pediatr. 2015; 174(6): 841-2. doi: 10.1007/s00431-014-2467-3. PMID: 25504357.

3) Tighe M, Afzal N, Bevan A, Hayen A, Munro A, Beattie R. Pharmacological treatment of children with gastro-oesophageal reflux. Cochrane Database Syst Rev. 2014; 24(11). doi: 10.1002/14651858.CD008550.pub2. PMID: 25419906.

4) Chiu CT, Hsu CM, Wang CC, Chang JJ, Sung CM, Lin CJ, et al. Randomised clinical trial: sodium alginate oral suspension is non-inferior to omeprazole in the treatment of patients with non-erosive gastroesophageal disease. Aliment Pharmacol Ther. 2013; 38(9): 1054-64. doi: 10.1111/apt.12482. PMID: 24024757.

5) Yoshida N, Kamada K, Tomatsuri N, Suzuki T, Takagi T, Ichikawa H, et al. Management of recurrence of symptoms of gastroesophageal reflux disease: synergistic effect of rebamipide with $15 \mathrm{mg}$ lansoprazole. Dig Dis Sci. 2010; 55(12): 3393-8. doi: 10.1007/s10620-010-1166-9. PMID: 20198424.

6) Fass R, Shapiro M, Dekel R, Sewell J. Systematic review: proton-pump inhibitor failure in gastrooesophageal reflux disease-where next?. Aliment Pharmacol Ther. 2005; 22(2): 79-94. doi: 10.1111/j.13652036.2005.02531.x. PMID: 16011666.

7) Zeng J, Zuo XL, Li YQ, Wei W, Lv GP. Tegaserod for dyspepsia and reflux symptoms in patients with chronic constipation: an exploratory open-label study. Eur J Clin Pharmacol. 2007; 63(6): 529-36. doi: 10.1007/s00228-007-0287-3. PMID: 17468863.

8) Jiang X, Lu FF, Wang WC, Liu YL. The characteristics of gastroesophageal reflux disease overlapping with functional bowel diseases in gastrointestinal clinic. Zhonghua Nei Ke Za Zhi. 2013; 52(10): 806-10. PMID: 24378054. 
9) Rasmussen S, Jensen TH, Henriksen SL, Haastrup PF, Larsen PV, SÃ ndergaard J, et al. Overlap of symptoms of gastroesophageal reflux disease, dyspepsia and irritable bowel syndrome in the general population. Scand J Gastroenterol. 2015; 50(2): 162-9. doi: 10.3109/00365521.2014.983157. PMID: 25525975.

10) Hosseini M, Salari M, Salari R. Psyllium seed may be effective in the treatment of gastroesophageal reflux disease (GERD) in patients with functional constipation. J Med Hypotheses Ideas. 2015; 9: S4-S7. doi: 10.1016/j.jmhi.2015.11.002.

11) Lee SY, Lee KJ, Kim SJ, Cho SW. Prevalence and risk factors for overlaps between gastroesophageal reflux disease, dyspepsia, and irritable bowel syndrome: a population-based study. Digestion. 2009; 79(3): 196-201. doi: 10.1159/000211715. PMID: 19342860.

12) Vakil N, Niklasson A, Denison H, Ryden A. Symptom profile in partial responders to a proton pump inhibitor compared with treatment-naïve patients with gastroesophageal reflux disease: a post hoc analysis of two study populations. BMC gastroenterology. 2014; 14: 177. doi: 10.1186/1471-230X-14-177. PMID: 25304129, PMCID: PMC4287106.

13) Kua $\mathrm{CH}, \mathrm{Ng} \mathrm{ST}$, Lhode R, Kowalski S, Gwee KA. Irritable bowel syndrome and other gastrointestinal disorders: evaluating self-medication in an Asian community setting. Int J Clin Pharm. 2012; 34(4): 561-8. doi: 10.1007/s11096-012-9644-0. PMID: 22552577.

14) Yarandi SS, Nasseri-Moghaddam S, Mostajabi P, Malekzadeh R. Overlapping gastroesophageal reflux disease and irritable bowel syndrome: increased dysfunctional symptoms. World journal of gastroenterology: World J Gastroenterol. 2010; 16(10): 1232. PMID: 20222167, PMCID: PMC2839176.

15) Lovell RM, Ford AC. Prevalence of gastro-esophageal reflux-type symptoms in individuals with irritable bowel syndrome in the community: a meta-analysis. Am J Gastroenterol. 2012; 107(12): 1793-801. doi: 10.1038/ajg.2012.336. PMID: 23032982.

16) Barratt SM, Leeds JS, Robinson K, Shah PJ, Lobo AJ, McAlindon ME, et al. Reflux and irritable bowel syndrome are negative predictors of quality of life in coeliac disease and inflammatory bowel disease. Eur J Gastroenterol Hepatol. 2011; 23(2): 159-65. doi: 10.1097/MEG.0b013e328342a547. PMID: 21178777.

17) de Bortoli N, Martinucci I, Bellini M, Savarino E, Savarino V, Blandizzi C, et al. Overlap of functional heartburn and gastroesophageal reflux disease with irritable bowel syndrome. World J Gastroenterol. 2013; 19(35): 5787. doi: 10.3748/wjg.v19.i35.5787. PMID: 24124323, PMCID: PMC3793133.

18) Lim CH, Choi MG, Baeg MK, Moon SJ, Kim JS, Cho YK, et al. Symptom characteristics and psychosomatic profiles in different spectrum of gastroesophageal reflux disease. Gut liver. 2014; 8(2): 1659. doi: 10.5009/gnl.2014.8.2.165, PMCID: PMC3964267.

19) Marlais M, Fishman JR, Koglmeier J, Fell JME, Rawat DJ. Reduced quality of life in children with Gastrooesophageal reflux disease. Acta Paediatr. 2010; 99(3): 418-21. doi: 10.1111/j.1651-2227.2009.01613.x. PMID: 19930192.

20) Pimentel M, Rossi F, Chow EJ, Ofman J, Fullerton S, Hassard P, et al. Increased prevalence of irritable bowel syndrome in patients with gastroesophageal reflux. J Clin Gastroenterol. 2002; 34(3): 221 -4. PMID: 11873099.

21) Pourhoseingholi A, Ashtari S, Pourhoseingholi MA, Moghimi-Dehkordi B, Safaee A, Zali MR. Irritable bowel syndrome, gastro-oesophageal reflux disease and dyspepsia: Overlap analysis using loglinear models. Arab J Gastroenterol. 2012; 13(1): 20-3. doi: 10.1016/j.ajg.2012.02.005. PMID: 22560820.

22) Salari R, Yousefi M, Salari M. Pharmacological treatment of chronic constipation: a literature review. Rev Clin Med. 2016; 3(3): 128-132. doi: 10.22038/rcm.2016.6818.

23) Zeitoun JD, Lefevre JH, de Parades V, Sejourne C, Sobhani I, Coffin B, et al. Functional Digestive Symptoms and Quality of Life in Patients with Ehlers-Danlos Syndromes: Results of a National Cohort Study on 134 Patients. PloS one. 2013; 8(11): e80321. doi: 10.1371/journal.pone.0080321. PMID: 24278273, PMCID: PMC3838387.

24) Chitkara DK, Talley NJ, Weaver AL, Katusic SK, De Schepper H, Rucker MJ, et al. Incidence of presentation of common functional gastrointestinal disorders in children from birth to 5 years: a cohort study. Clin Gastroenterol Hepatol. 2007; 5(2): 186-91. doi: 10.1016/j.cgh.2006.06.012. PMID: 16901769.

25) Breckan RK, Asfeldt AM, Straume B, Florholmen J, Paulssen EJ. Prevalence, comorbidity, and risk factors for functional bowel symptoms: a population-based survey in Northern Norway. Scand J Gastroenterol. 2012; 47(11): 1274-82. doi: 10.3109/00365521.2012.688215. PMID: 23061445.

26) Monnikes H, Schwan T, Rensburg C, Straszak A, Theek C, Sander P, et al. Randomised clinical trial: sustained response to PPI treatment of symptoms resembling functional dyspepsia and irritable bowel 
syndrome in patients suffering from an overlap with erosive gastro-oesophageal reflux disease. Aliment Pharmacol Ther. 2012; 35(11): 1279-89. doi: 10.1111/j.1365-2036.2012.05085.x. PMID: 22486552.

27) Yamaji Y, Isomura Y, Yoshida S, Yamada A, Hirata Y, Koike K. Randomized controlled trial comparing the efficacy of mosapride plus omeprazole combination therapy to omeprazole monotherapy in gastroesophageal reflux disease. J Dig Dis. 2014; 15(9): 469-76. doi: 10.1111/1751-2980.12167. PMID: 24957863.

28) Remes-Troche JM, Sobrino-Cossio S, Soto-Perez JC, Teramoto-Matsubara O, Morales-Arambula M, Orozco-Gamiz A, et al. Efficacy, Safety, and Tolerability of Pantoprazole Magnesium in the Treatment of Reflux Symptoms in Patients with Gastroesophageal Reflux Disease (GERD): A Prospective, Multicenter, Post-Marketing Observational Study. Clin Drug Investig. 2014; 34(2): 83-93. doi: 10.1007/s40261-0130135-4. PMID: 24347282.

29) Moraes-Filho JP, Pedroso M, Quigley EMM. Randomised clinical trial: daily pantoprazole magnesium 40 $\mathrm{mg}$ vs. esomeprazole $40 \mathrm{mg}$ for gastro-oesophageal reflux disease, assessed by endoscopy and symptoms. Aliment Pharmacol Ther. 2014; 39(1): 47-56. doi: 10.1111/apt.12540. PMID: 24299323.

30) Yu YY, Fang DC, Fan LL, Chang H, Wu ZL, Cao Y, et al. Efficacy and safety of esomeprazole with flupentixol/melitracen in treating gastroesophageal reflux disease patients with emotional disorders. J Gastroenterol Hepatol. 2014; 29(6): 1200-6. PMID: 24955450.

31) Abbasinazari M, Panahi Y, Mortazavi SA, Fahimi F, Valizadegan G, Mohtashami R, et al. Effect of a Combination of Omeprazole Plus Sustained Release Baclofen Versus Omeprazole Alone on Symptoms of Patients with Gastroesophageal Reflux Disease (GERD). Iran J Pharm Res. 2014; 13(4): 1221-6. PMID: 25587310 , PMCID: PMC4232787.

32) Orbelo DM, Enders FT, Romero Y, Francis DL, Achem SR, Dabade TS, et al. Once-daily omeprazole/sodium bicarbonate heals severe refractory reflux esophagitis with morning or nighttime dosing. Dig Dis Sci. 2015; 60(1): 146-62. doi: 10.1007/s10620-013-3017-y. PMID: 24448652.

33) Nagahara A, Hojo M, Asaoka D, Sasaki H, Watanabe S. A randomized prospective study comparing the efficacy of on-demand therapy versus continuous therapy for 6 months for long-term maintenance with omeprazole $20 \mathrm{mg}$ in patients with gastroesophageal reflux disease in Japan. Scand J Gastroenterol. 2014; 49(4): 409-17. doi: 10.3109/00365521.2013.878380. PMID: 24444414, PMCID: PMC4002634.

34) Kim SE, Kim N, Oh S, Kim HM, Park MI, Lee DH, et al. Predictive Factors of Response to Proton Pump Inhibitors in Korean Patients With Gastroesophageal Reflux Disease. J Neurogastroenterol Motil. 2015; 21(1): 69-77. doi: 10.5056/jnm14078. PMCID: PMC4288103, PMCID: PMC4288103.

35) de Milliano I, Tabbers MM, van der Post JA, Benninga MA. Is a multispecies probiotic mixture effective in constipation during pregnancy? 'A pilot study'. Nutr J. 2012; 11(8): 1-6. doi: 10.1186/1475-2891-11-80. PMID: 23035837, PMCID: PMC3502183.

36) Perry KA, Pham TH, Spechler SJ, Hunter JG, Melvin WS, Velanovich V. 2014 SSAT State-of-the-Art Conference: Advances in Diagnosis and Management of Gastroesophageal Reflux Disease. J Gastrointest Surg. 2015; 19(3): 458-66. doi: 10.1007/s11605-014-2724-9. PMID: 25519085.

37) Boltin D, Boaz M, Aizic S, Sperber A, Fass R, Niv Y, et al. Psychological distress is not associated with treatment failure in patients with gastroesophageal reflux disease. J Psychosom Res. 2013; 75(5): 462-6. doi: 10.1016/j.jpsychores.2013.08.008. PMID: 24182636.

38) Sakamoto $Y$, Inamori M, Iwasaki T, Lida H, Endo H, Hosono K, et al. Relationship between upper gastrointestinal symptoms and diet therapy: examination using frequency scale for the symptoms of gastroesophageal reflux disease. Hepatogastroenterology. 2009; 57(104): 1635-8. PMID: 21443134.

39) Heine RG. Allergic gastrointestinal motility disorders in infancy and early childhood. Pediatr Allergy Immunol. 2008; 19(5): 383-91. doi: 10.1111/j.1399-3038.2008.00785.x. PMID: 18713339.

40) Butt AK, Hashemy I. Risk factors and prescription patterns of gastroesophageal reflux disease: HEAL study in Pakistan. J Pak Med Assoc. 2014; 64(7): 751-7. PMID: 25255580.

41) Kawano S, Murata H, Tsuji S, Kubo M, Tatsuta M, Iishi H, et al. Randomized comparative study of omeprazole and famotidine in reflux esophagitis. J Gastroenterol Hepatol. 2002; 17(9): 955-9. PMID: 12167115.

42) Metz DC, Bochenek WJ. Pantoprazole maintenance therapy prevents relapse of erosive oesophagitis. Aliment Pharmacol Ther. 2003; 17(1): 155-64. PMID: 12492745.

43) Inadomi JM, McIntyre L, Bernard L, Fendrick AM. Step-down from multiple-to single-dose proton pump inhibitors (PPIs): a prospective study of patients with heartburn or acid regurgitation completely relieved with PPIs. Am J Gastroenterol. 2003; 98(9): 1940-4. doi: 10.1111/j.1572-0241.2003.07665.x. PMID: 14499769. 
44) Saitoh $T$, Otsuka H, Kawasaki $T$, Endo H, Iga $D$, Tomimatsu $M$, et al. Influences of CYP2C19 polymorphism on recurrence of reflux esophagitis during proton pump inhibitor maintenance therapy. Hepatogastroenterology. 2009; 56(91-92): 703-6. PMID: 19621685.

45) Bate CM, Green JRB, Axon ATR, Tildesley G, Murray FE, Owen SM, et al. Omeprazole is more effective than cimetidine in the prevention of recurrence of GERD-associated heartburn and the occurrence of underlying oesophagitis. Aliment Pharmacol Ther. 1998; 12: 41-7. PMID: 9692699.

46) Usai P, Manca R, Cuomo R, Lai MA, Russo L, Boi MF. Effect of gluten-free diet on preventing recurrence of gastroesophageal reflux disease-related symptoms in adult coeliacpatients with nonerosive reflux disease. J Gastroenterol Hepatol. 2008; 23(9): 1368-72. doi: 10.1111/j.1440-1746.2008.05507.x. PMID: 18853995.

47) Miyake S, Yamada M, Iwamoto H, Yamashita S, Sugio Y. Effect of a new H2-blocker, famotidine, in reflux esophagitis among severely handicapped children. Clin ther. 1986; 9(5): 548-58. PMID: 2889529.

48) Caro JJ, Salas M, Ward A. Healing and relapse rates in gastroesophageal reflux disease treated with the newer proton-pump inhibitors lansoprazole, rabeprazole, and pantoprazole compared with omeprazole, ranitidine, and placebo: evidence from randomized clinical trials. Clin ther. 2001; 23(7): 998-1017. PMID: 11519776. 